\title{
RANCANGAN APLIKASI ANDROID UNTUK PENCARIAN LOKASI WISATA DI KOTA BANDA ACEH
}

\author{
Mukti Qamal ${ }^{1}$ \\ Jurusan Teknik Informatika, Fakultas Teknik, Universitas Malikussaleh \\ mukti.qamal@unimal.ac.id
}

\begin{abstract}
Abstrak
Abstrak - Banda Aceh merupakan kota dimana bidang pariwisatanya sedang mengalami perkembangan yang pesat. Para wisatawan dari luar Aceh, khususnya yang baru pertama kali mengunjungi kota Banda Aceh akan sedikit kesulitan dalam mengakses tempat-tempat wisata di kota ini karena tidak mengetahui secara detail informasi mengenai lokasi tempattempat wisata tersebut. Tujuan dari penelitian ini adalah membangun sebuah Sistem Informasi Geografis berbasis mobile tentang pariwisata Banda Aceh, yang diharapkan dapat membantu wisatawan local ataupun asing dalam memilih lokasi wisata yang ingin dikunjungi dan merekomendaisikan rute terdekat dari posisi user ke tempat wisata tersebut. Metode yang menjadi dasar dalam perancangan SIG ini adalah metode Graf, dengan menerapkan algoritma pencarian rute terpendek yaitu algoritma Dijkstra. Selain itu, sistem ini akan menggunakan Haversine Formula dalam mengkalkulasikan jarak, yaitu jarak antara posisi user ke satu tempat wisata. Hasil dari penelitian ini adalah aplikasi berbasis Mobile Web dua bahasa yang dapat menginformasikan lokasi-lokasi wisata yang ada serta menampilkan rute terdekat dari posisi user menuju ke tempat wisata tersebut.
\end{abstract}

Kata Kunci : Peta wisata, Mobile GIS, Algoritma Dijkstra, Rute Terpendek 


\section{Pendahuluan}

Setelah kejadian tsunami, kota Banda Aceh menjadi salah satu kota yang sangat diminati dalam hal pariwisata di Indonesia. Dalam pengaksesan tempat-tempat wisata tersebut bagi para pelancong dari luar daerah, akan sedikit kesulitan dalam mengakses tempat wisata tersebut karena tidak mengetahui secara detail tempat-tempat wisata di kota yang baru mereka kunjungi. Untuk itu perlu dirancang sebuah layanan informasi yang dapat diakses melalui berbagai perangkat mobile yang dapat membantu wisatawan lokal dan internasional dari luar daerah kota Banda Aceh dalam memudahkan serta mempercepat pencarian informasi mengenai tempat-tempat wisata di kota Banda Aceh.

Penerapan Sistem Informasi Geografis (SIG) berbasis mobile web merupakan salah satu cara untuk membantu para wisatawan dalam mengakses tempat-tempat wisata yang ada di Kota Banda Aceh, karena perangkat mobile merupakan perangkat yang sudah lazim dipunyai oleh setiap wisatawan saat ini. Sistem ini nantinya akan dirancang agar pengguna mendapat informasi lengkap mengenai tempat-tempat wisata tersebut dan memperoleh navigasi rute terpendek ke tempat wisata tersebut, melalui perangkat mobile dengan mengimplementasikan algoritma Djikstra, sehingga wisatawan dapat menggunakan waktu secara efisien selama mengunjungi tempat-tempat wisata di Banda Aceh. Aplikasi ini akan menggunakan dua bahasa yaitu bahasa Indonesia dan bahasa Inggris sehngga bisa digunakan baik oleh wisatawan local atau wisatawan mancanegara.

\section{Metode Penelitian}

Dalam pengembangan system, digunakan langkahlangkah :

1. Analisis Kebutuhan

Membuat analisa terhadap data yang sudah diperoleh dari hasil observasi pada objek yang dituju, yaitu dengan menggabungkan laporan survey dan kebijakan pemakai menjadi spesifikasi yang terstruktur dengan menggunakan pemodelan.

2. Perancangan Sistem

Memahami rancangan sistem informasi sesuai data 
yang ada dan mengimplementasikan model yang diinginkan oleh pemakai. Pemodelan yang digunakan dalam sistem ini yaitu menggunakan Diagram UML, serta perancangan Database yang berguna untuk mempermudah dalam proses-proses selanjutnya.

\section{Hasil dan Pembahasan}

A. Use Case Diagram

Use Case Diagram dapat digunakan untuk menyusun requirement sebuah sistem, mengkomunikasikan rancangan dengan klien, dan merancang test case untuk semua feature yang ada pada sistem. Gambar 3.1 menunjukkan diagram Use Case.

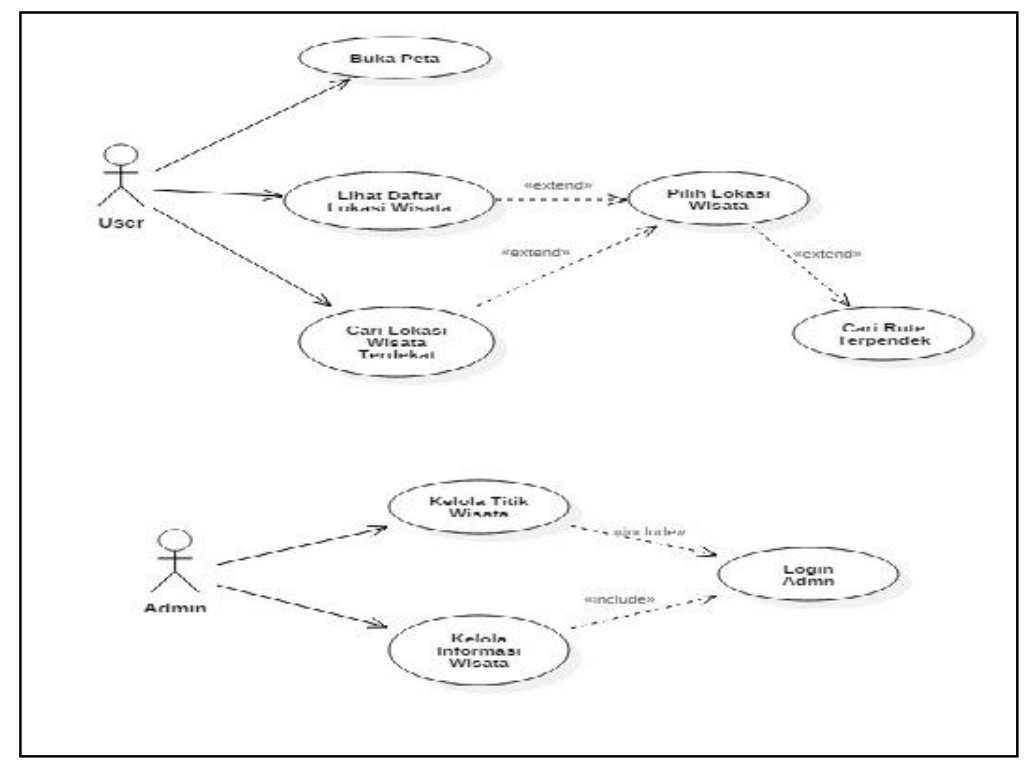

B. Activity Diagram

Diagram aktivitas atau activity diagram menggambarkan aliran fungsionalitas sistem. Ada beberapa diagram aktivitas dalam perancangan ini, yaitu sebagai berikut :

a. Activity Diagram Buka Peta

Pada aktivitas yang ada dalam menu Buka Peta yang akan dilakukan yaitu. 
1. Proses mencari posisi pengguna dimana pengguna akan menggunakan GPS yang akan mencari koordinat pengguna pada prosesnya, yang mana diperlukan koneksi internet yang baik.

2. Menampilkan posisi pengguna dan titik-titik lokasi wisata pada peta, dimana aplikasi akan mengirimkan datanya berupa koordinat GPS ke server Google Maps untuk mendapatkan posisi user dan titik-titik lokasi wisata dan harus terkoneksi internet yang baik. Diagram aktifitas Buka Peta dapat dilihat di Gambar 3.2.

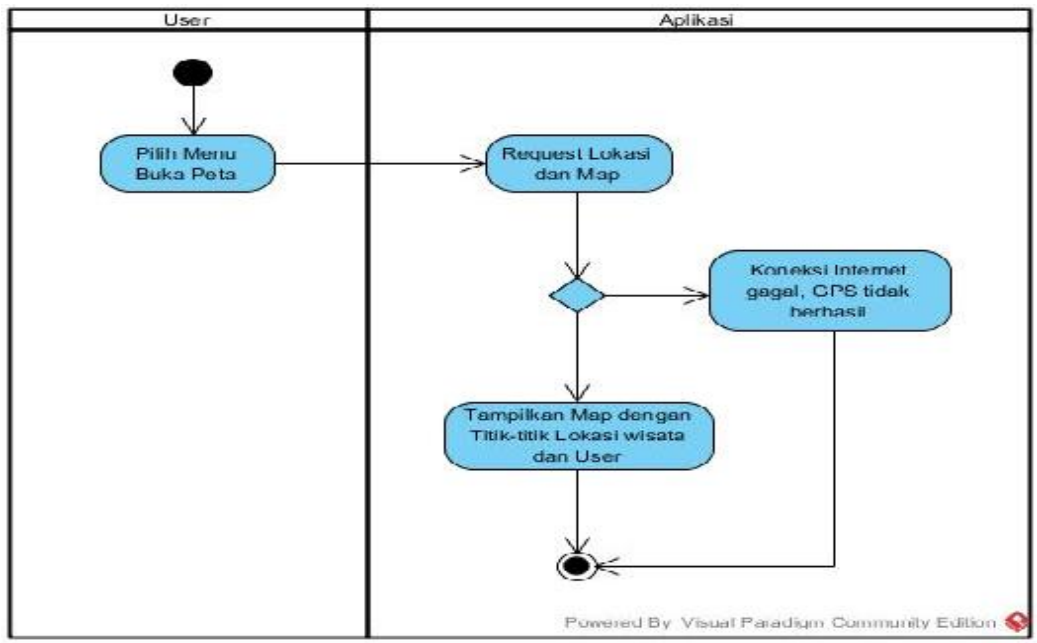

Gambar 3.2 Activity Diagram Buka Peta

b. Activity Diagram Lihat Daftar Lokasi Wisata

Aktivitas diagram menampilkan Daftar lokasi wisata di Banda Aceh. Aktivitas diagram menu daftar lokasi wisata ditunjukkan pada Gambar 3.3. 


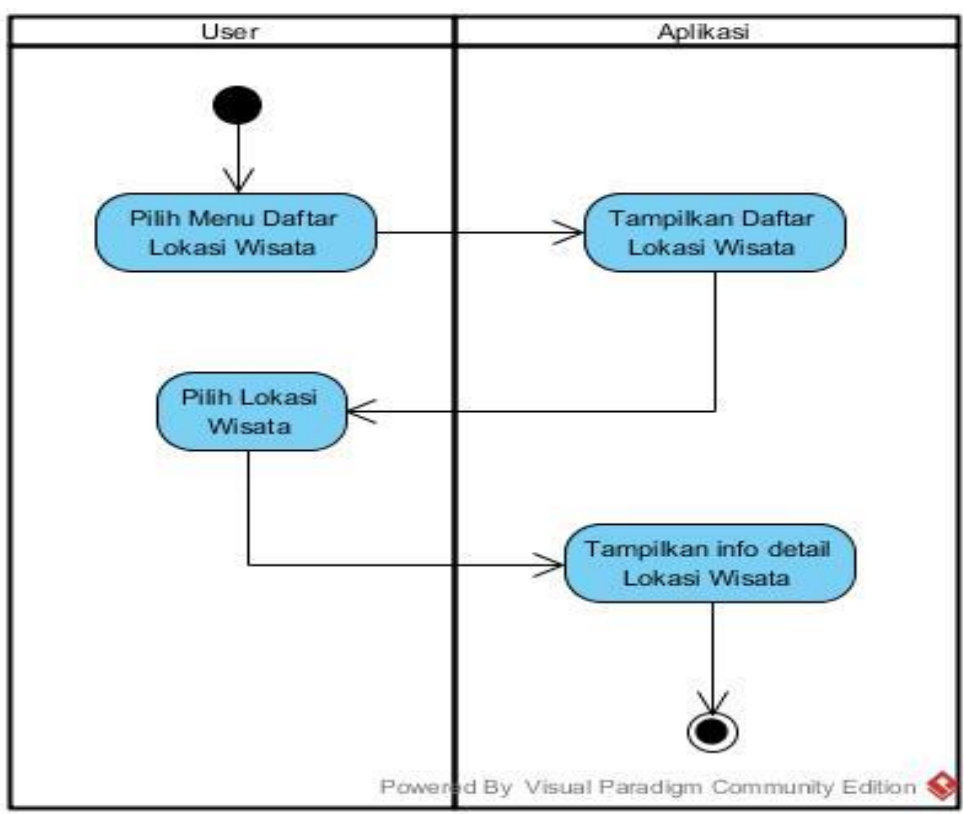

Gambar 3.3 Activity Diagram menampilkan Lihat Daftar Lokasi Wisata

c. Activity Diagram Cari Rute Terpendek

Proses ini menerangkan tentang penunjuk arah yang dapat dilihat oleh pengguna. Apabila pengguna masuk pada menu cari rute, maka pengguna dapat memilih untuk mencari rute terpendek dari posisi pengguna ke lokasi wisata atau dari satu lokasi lain ke lokasi wisata yang akan dituju dan setelah itu akan tampil peta beserta marker-marker yang telah dimasukan berdasarkan koordinat. Pada marker tersebut terdapat informasi nama tempat dan rute alamat dari lokasi tujuan tersebut. Diagram aktifitas Cari Rute Terpendek dapat dilihat pada Gambar 3.4. 


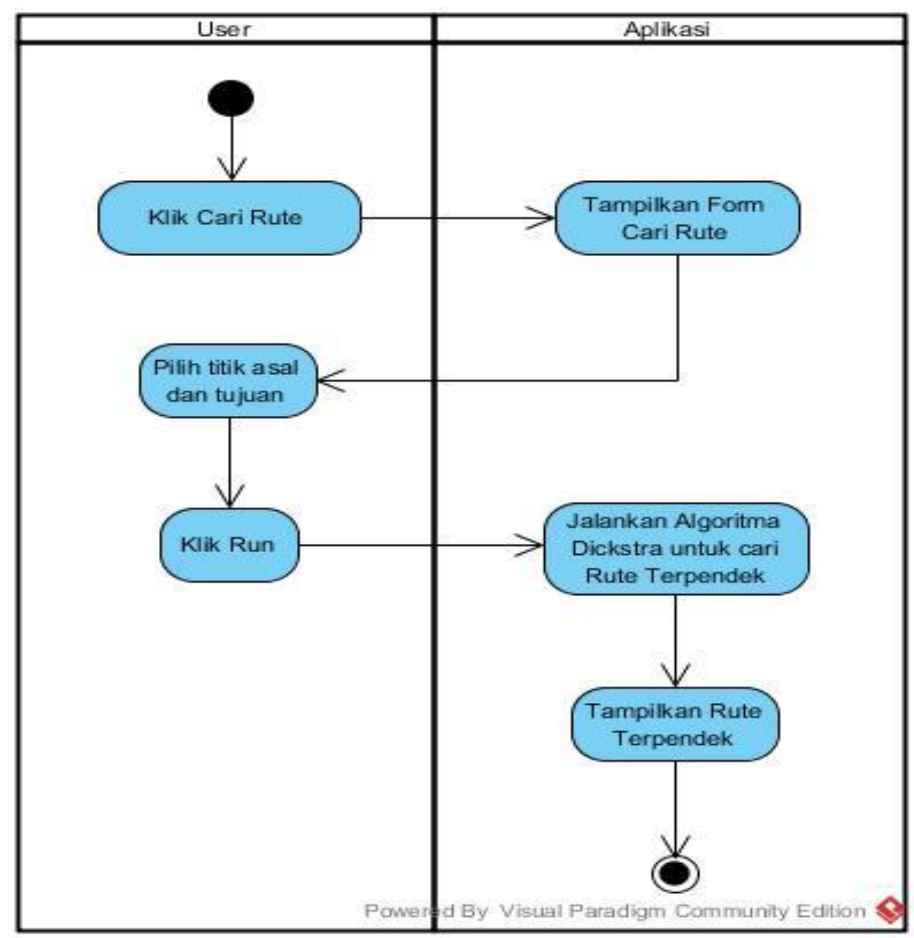

Gambar 3.4 Activity Diagram Cari Rute Terpendek

\section{d. Activity Diagram Cari Lokasi Wisata Terdekat}

Proses ini akan menampilkan daftar lokasi wisata mulai dari yang terdekat dengan pengguna. Jadi pengguna agar tidak bingung ingin memilih tempat wisata yang terdekat dengan posisi pengguna atau memilih tempat wisata lainnya. Proses aktivitas Cari lokasi wisata terdekat ditunjukkan pada Gambar 3.5. 


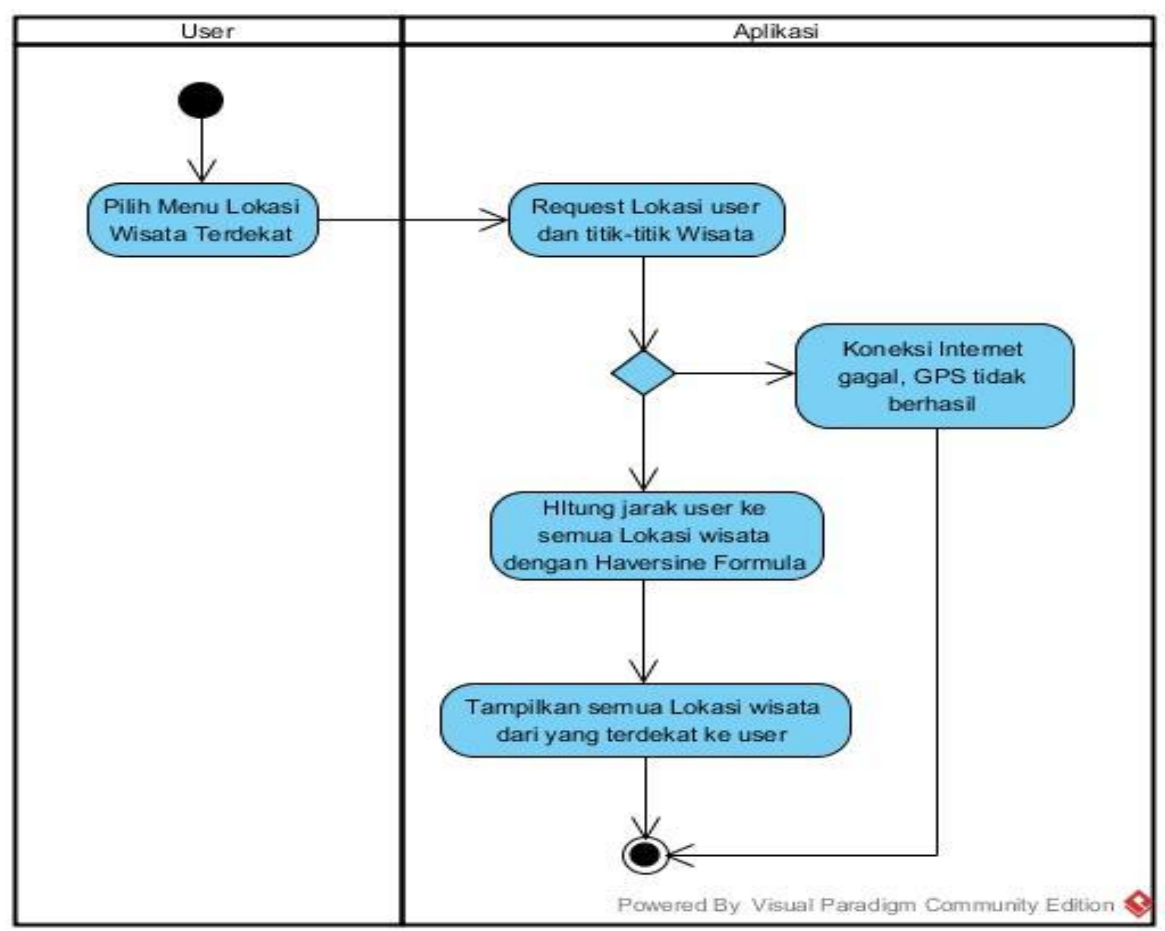

Gambar 3.5 Activity Diagram Cari Lokasi Wisata Terdekat

C. Sequence Diagram

Diagram sekuensial atau sequence diagram digunakan untuk menunjukan aliran fungsionalitas dalam use case. Pada aplikasi ini terdapat beberapa sequence diagram, yaitu sebagai berikut:

a. Sequence Diagram Buka Peta

Pada diagram sekuen Buka Peta ketika pengguna memilih menu Buka Peta maka akan ada permintaan ke GPS server lalu akan diteruskan ke JSON server dan Google Maps Server yang berguna untuk meminta peta beserta titik-titik lokasi wisata dan lokasi pengguna berada secara realtime. Namun apabila koneksi internet lambat atau tidak adanya koneksi internet maka proses tersebut akan gagal. Sequence diagram Buka Peta dapat dilihat pada gambar 3.6. 


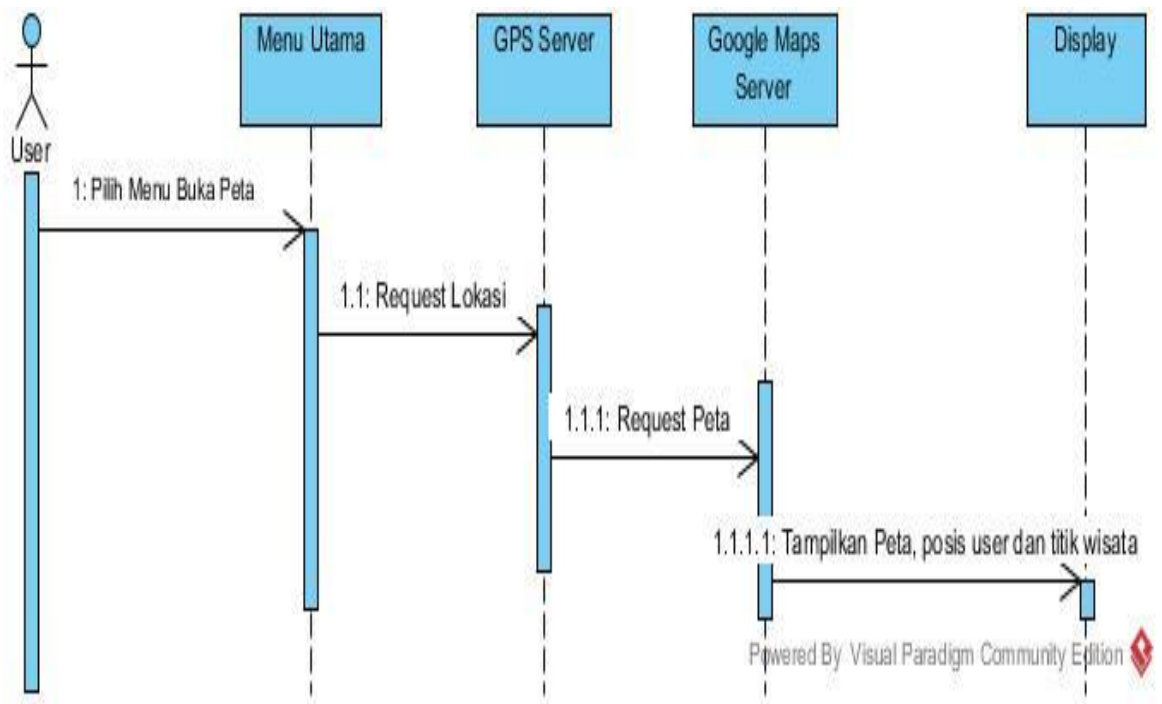

Gambar 3.6. Sequence Diagram Buka Peta

b. Sequence Diagram Lihat Daftar Lokasi Wisata

Diagram sekuen Lihat Daftar Lokasi Wisata merupakan proses untuk melihat daftar tempat wisata yang ada di kota Banda Aceh. Pada daftar lokasi wisata terdapat nama tempat wisata beserta gambar lokasi. Pengguna mengklik link nama tempat wisata lalu akan direspon oleh sistem untuk ditampilkan deskripsi lokasi tempat tersebut. . Sequence diagram Lihat Daftar Lokasi Wisata dapat dilihat pada Gambar 3.7. 


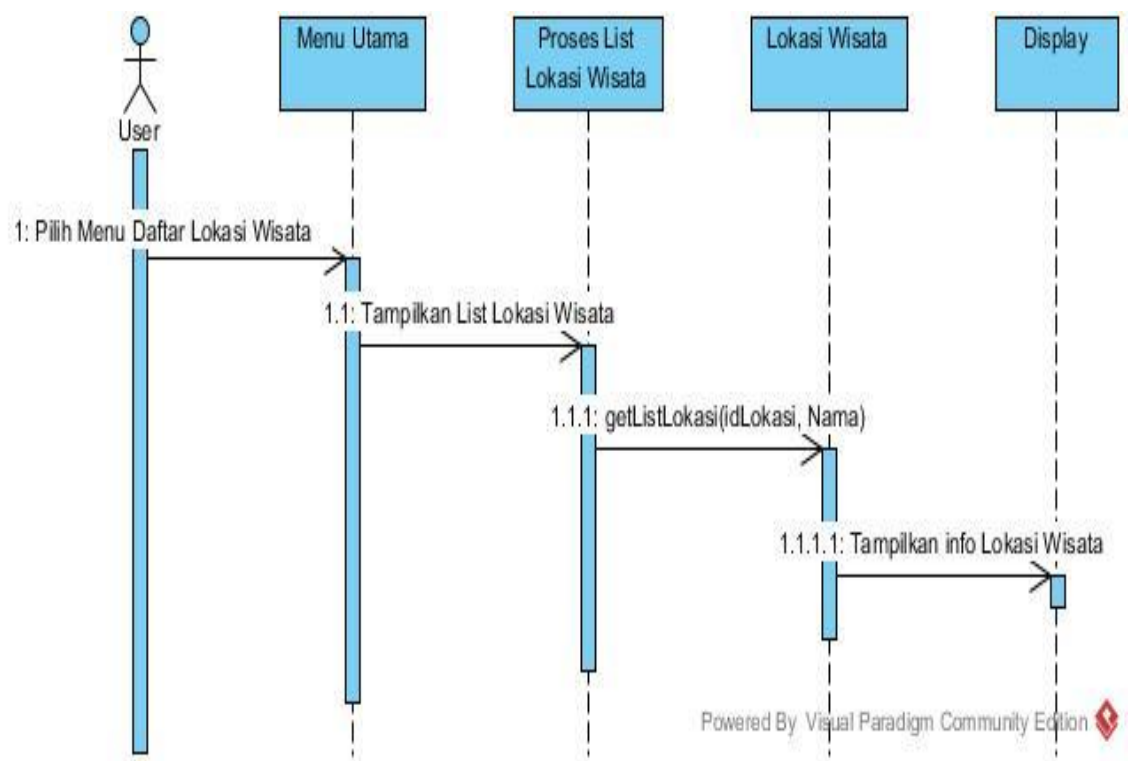

Gambar 3.7. Diagram Sekuen Lihat Daftar Lokasi Wisata

c. Sequence Diagram Cari Rute Terpendek

Pada diagram sekuen Cari Rute Terpendek, ketika pengguna memilih menu Cari Rute maka aplikasi akan mempekerjakan algoritma Dijkstra untuk mendapatkan rute terpendek. Rute yang ditemukan akan ditampilkan dilayar aplikasi. Sequence diagram Cari Rute Terpendek dapat dilihat pada Gambar 3.8. 


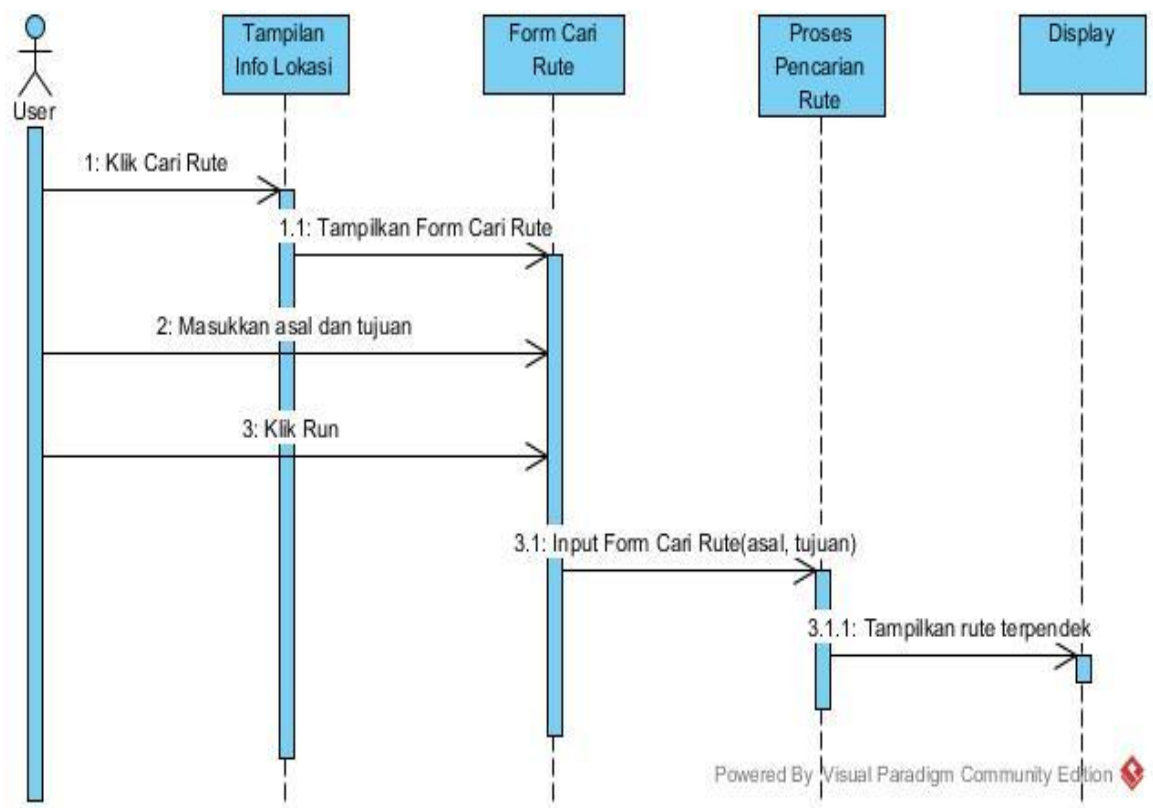

Gambar 3.8 Diagram Sekuen Cari Rute Terpendek

d. Sequence Diagram Cari Lokasi Wisata Terdekat

Pada diagram sekuen lokasi terdekat, ketika pengguna memilih menu ini maka aplikasi akan menghitung jarak dari pengguna ke semua lokasi wisata dengan menggunakan Haversine Formula, kemudian menampilkan daftar lokasi wisata dengan diurutkan dari yang terdekat dari pengguna. Diagram sekuen Cari Lokasi wisata terdekat dapat dilihat pada Gambar 3.9. 


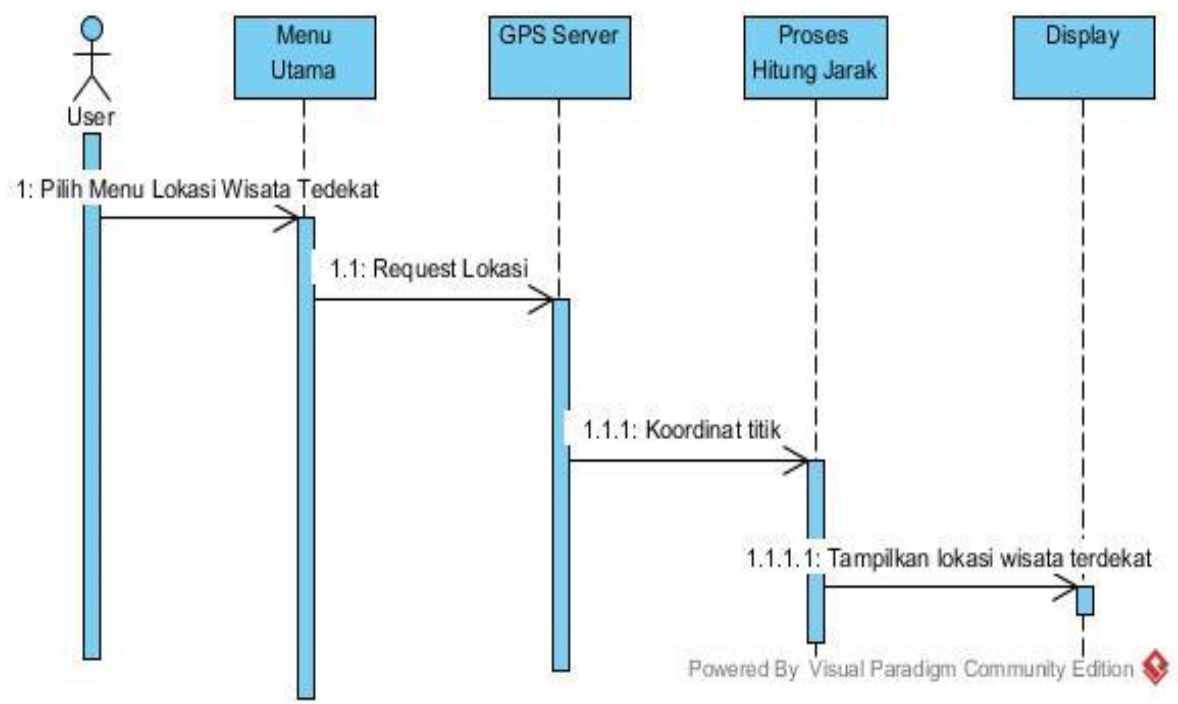

Gambar 3.9 Sequence diagram Cari Lokasi Wisata Terdekat

D. Perancangan Basis Data

Rancangan basis data terdiri dari satu tabel yang bernama "Wisata". Ada 9 buah field pada table Wisata, yaitu id_wisata, nama, alamat, gambar, ,jenis, lat dan long. Berikut merupakan gambaran dari struktur tabel Wisata.

Tabel 3.1 Struktur Tabel Wisata

\begin{tabular}{|c|c|c|c|}
\hline Field & Type data & Panjang Field & Keterangan \\
\hline Id_Lokasi & numeric & 10 & Primary Key \\
\hline Nama & varchar & 60 & \\
\hline Alamat & varchar & 100 & \\
\hline Gambar & varchar & 200 & \\
\hline Jenis & varchar & 100 & \\
\hline Lat & double & - & \\
\hline Long & double & - & \\
\hline
\end{tabular}


E. Perancangan Antarmuka

a. Perancangan Menu Utama

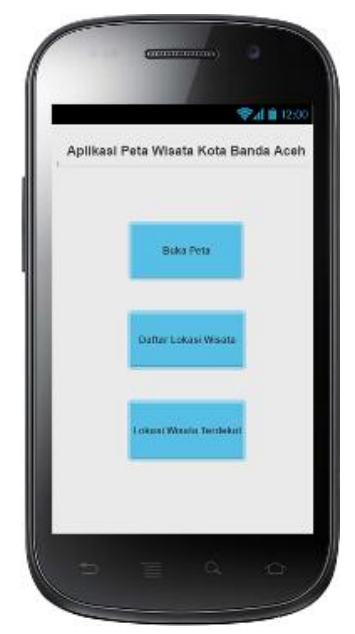

Gambar 3.10 Tampilan Menu Utama

Menu Utama merupakan tampilan yang pertama kali dilihat saat aplikasi dijalankan. Menu yang tersedia adalah :

- Buka Peta

- Daftar Lokasi Wisata

- Lokasi Wisata Terdekat

b. Perancangan Menu Buka Peta

Buka Peta yang digunakan untuk membuka peta kota Banda Aceh yang disertai titik-titik lokasi wisata dan posisi pengguna. Ketika sebuah titik lokasi wisata di-klik akan menampilkan deskripsi lokasi wisata tersebut. Tampilan Buka Peta dapat dilihat pada Gambar 3.11. 


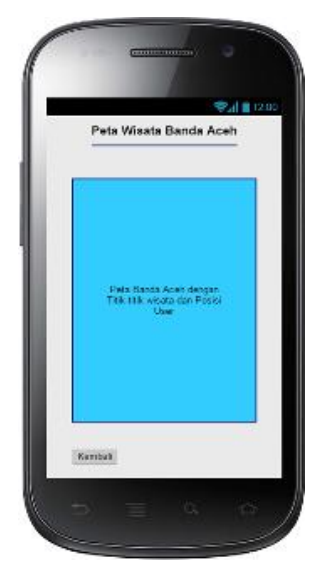

Gambar 3.11 Tampilan Buka Peta

c. Perancangan Menu Daftar Lokasi Wisata

Menu Daftar Lokasi Wisata digunakan untuk menampilkan daftar tempat-tempat wisata di kota Banda Aceh, seperti pada gambar 3.12.

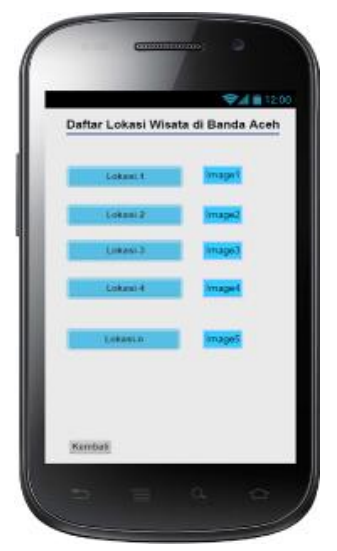

Gambar 3.12 Tampilan Buka Peta

Jika di-klik salah satu tempat wisata akan muncul layar baru yang menampilkan informasi detail tentang lokasi wisata tersebut dan tombol Cari Rute, seperti pada gambar 3.13. 


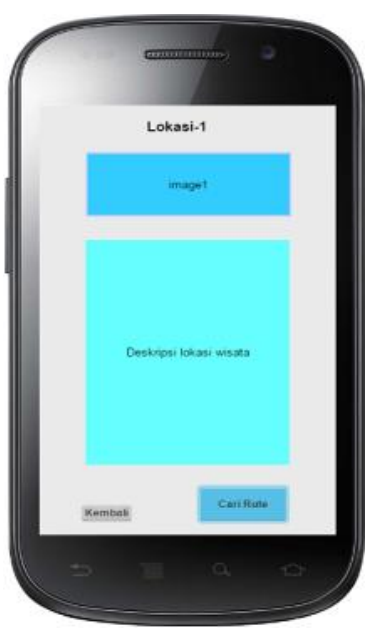

Gambar 3.13 Tampilan informasi Lokasi Wisata yang Dipilih

Menekan tombol Cari Rute akan membuka layar Cari Rute yang meminta masukan awal dan tujuan rute seperti pada gambar 3.14 .

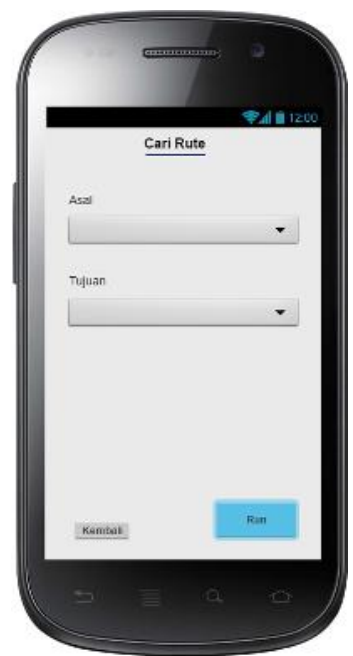

Gambar 3.14 Tampilan Cari Rute

Menekan tombol Run akan mengaktifkan algoritma Dijkstra untuk mencari jalur terpendek baik dari posisi pengguna ataupun dari titik-titik lannya ke lokasi wisata yang diingiinkan . Eksekusi 
algoritma tersebut akan menghasilkan rute terpendek beserta dengan peta rute, seperti bisa dilihat pada gambar 3.15.

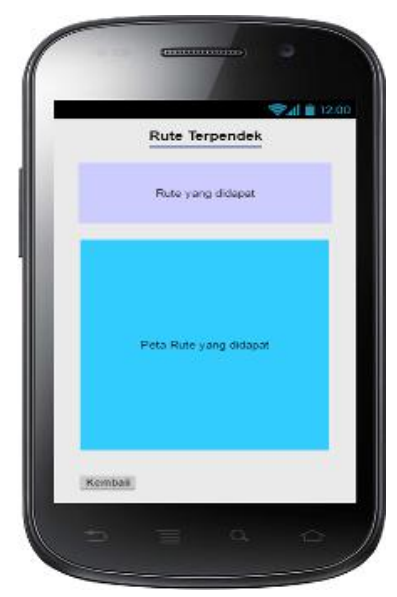

Gambar 3.15. Tampilan Rute yang Didapat

\section{d. Perancangan Menu Lokasi Wisata Terdekat}

Lokasi Wisata Terdekat digunakan untuk menampilkan daftar lokasi wisata yang diurutkan mulai dari yang terdekat dengan pengguna. Antarmuka ini dapat dilihat pada gambar 3.16.

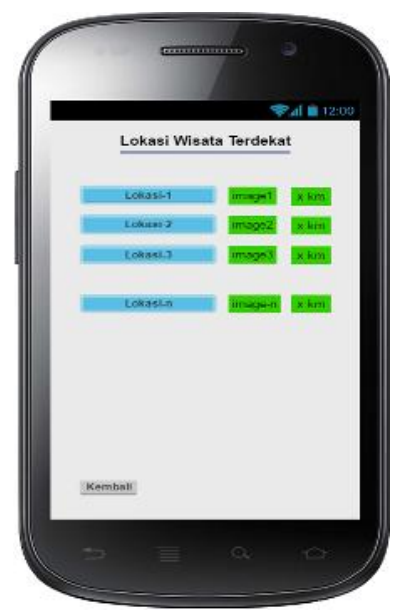

Gambar 3.16. Tampilan Lokasi Wisata Terdekat 


\section{Kesimpulan dan Saran}

Dari perancangan aplikasi yang telah dilakukan, dapat disimpulkan bahwa :

1. Aplikasi dapat menampilkan posisi user dan lokasi wisata disekitarnya serta merekomendasikan lokasi wisata terdekat beserta informasi lengkap tentang lokasi tersebut,

2. Aplikasi system informasi geografis di Kota Banda Aceh berbasis mobile android memberikan kemudahan bagi masyarakat kota Banda Aceh dan para traveller untuk mendapatkan lokasi wisata yang tepat sesuai yang diinginkan dan dapat dimaksimalkan penggunanya karena kemudahan penggunaan aplikasi melalui smartphone android 


\section{Daftar Pustaka}

Denny Charter. 2004. Desain dan Aplikasi GIS. Jakarta: PT. Elex Media Komputindo.

Eddy Prahasta. 2009. Sistem Informasi Geografi : Konsep-Konsep Dasar (Perspektif Geodesi \& Geomatika). Bandung, CV Informatika.

Eddy Prahasta. 2007. Sistem Informasi Geografis: Membangun Aplikasi Web-Based GIS Dengan MapServer. Bandung: C.V Informatika.

Indra Jati Kusuma. 2013. Sistem Informasi Geografis Pariwisata Pulau Lombok Berbasis Android. Program Studi Teknik Informatika Universitas Islam Negeri Sunan Kalijaga Yogyakarta.

Stan Aronoff. 1991. "Geographical Information System: A Management Perspective". Ottawa, Canada: WDL Publications.

Stephanus Hermawan S. 2011. Mudah Membuat Aplikasi Android. Yogyakarta: Penerbit Andi.

Widy Sulistianto. 2012. Aplikasi Mobile GIS Berbasis Android Lokasi Perguruan Tinggi Provinsi Daerah Istimewa Yogyakarta. Teknik Informatika FT Industri Universitas Pembangunan Nasional "Veteran" Yogyakarta. 